\title{
Comparison of 2D Finite Element Modeling Assumptions with Results From 3D Analysis for Composite Skin-Stiffener Debonding
}

\author{
Ronald Krueger ${ }^{+}$Isabelle L. Paris ${ }^{*}$, and T. Kevin O'Brien ${ }^{* *}$ \\ NASA Langley Research Center, Hampton, Virginia \\ Pierre J. Minguet ${ }^{\dagger}$ \\ The Boeing Company, Philadelphia, Pennsylvania
}

\begin{abstract}
The influence of two-dimensional finite element modeling assumptions on the debonding prediction for skin-stiffener specimens was investigated. Geometrically nonlinear finite element analyses using two-dimensional plane-stress and plane-strain elements as well as three different generalized plane strain type approaches were performed. The computed skin and flange strains, transverse tensile stresses and energy release rates were compared to results obtained from three-dimensional simulations. The study showed that for strains and energy release rate computations the generalized plane strain assumptions yielded results closest to the full three-dimensional analysis. For computed transverse tensile stresses the plane stress assumption gave the best agreement. Based on this study it is recommended that results from plane stress and plane strain models be used as upper and lower bounds. The results from generalized plane strain models fall between the results obtained from plane stress and plane strain models. Twodimensional models may also be used to qualitatively evaluate the stress distribution in a ply and the variation of energy release rates and mixed mode ratios with delamination length. For more accurate predictions, however, a three-dimensional analysis is required.
\end{abstract}

\section{BACKGROUND}

Many composite components in aerospace structures are made of flat or curved panels with cocured or adhesively bonded frames and stiffeners. Previous investigations of the failure of secondary bonded structures focused on loading conditions typically experienced by aircraft crown fuselage panels. Tests were conducted with specimens cut from a full-size panel to verify the integrity of the bondline between the skin and the flange or frame [1]. A simpler and cheaper specimen configuration that would allow detailed observations of the failure mechanism at the skin/flange interface was proposed in reference [2]. The investigations focused on the failure mechanisms of a bonded skin/flange coupon configuration subjected to tension, three and four-point bending, and combined tension/bending loading [3-6].

\footnotetext{
${ }^{+}$ICASE Staff Scientist.

* National Research Council Fellow.

** Senior Aerospace Engineer, U.S. Army Research Laboratory, Vehicle Technology Directorate.

${ }^{\dagger}$ Head Structures Technology Research and Development Group.
} 
An analytical methodology was also developed to predict the location and orientation of the first transverse matrix crack based on the principal transverse tension stress distribution in the off axis plies nearest the bondline in the vicinity of the flange tip [7]. Earlier investigations [2,3] indicated that the matrix cracking occurred when the maximum principal transverse tensile stress, $\sigma_{\mathrm{tt}}$, normal to the fiber direction, as calculated by

$$
\sigma_{\mathrm{tt}}=\frac{\sigma_{22}+\sigma_{33}}{2}+\sqrt{\left(\frac{\sigma_{22}-\sigma_{33}}{2}\right)^{2}+\tau_{23}^{2}}
$$

reached the transverse tension strength of the material. Here $\sigma_{22}$ and $\sigma_{33}$ denote the normal stresses and $\tau_{23}$ the shear stress in the 2-3 plane perpendicular to the fiber direction.

A fracture mechanics approach was used to investigate delamination onset once the initial crack had formed. The initial crack was modeled as a discrete discontinuity at a location suggested by the microscopic investigation. The Virtual Crack Closure Technique (VCCT) was used to calculate mixed mode strain energy release rates $G_{\mathrm{I}}$ (due to crack opening), $G_{\mathrm{II}}$, (due to in-plane shear) and $G_{\mathrm{III}}$ (due to inplane scissoring) [8-10]. Computed total strain energy release rates, $G_{\mathrm{T}}$, were compared to the critical value, $G_{\mathrm{c}}$, of the material for the appropriate mixed mode ratio $\left(G_{\mathrm{II}} / G_{\mathrm{T}}\right)$ in order to determine the potential for delamination growth [7].

\section{INTRODUCTION}

The current study focused on skin-stiffener debonding resulting from buckling of a thin-gage composite fuselage structure as described in reference [7]. The specimens consisted of a bonded skin and flange assembly as shown in Figure 1(a). An IM7/8552 graphite/epoxy system was used for both the skin and flange. The skin was made of prepreg tape with a measured average ply thickness of $h=0.148 \mathrm{~mm}$ and had a [45/-45/0/-45/45/90/90/-45/45/0/45/-45] lay-up. The flange was made of a plain-weave fabric with a thickness of $h=0.212 \mathrm{~mm}$. The flange lay-up was [45/0/45/0/45/0/45/0/45 $]_{\mathrm{f}}$, where the subscript "f" denotes fabric, " 0 " represents a $0^{\circ}-90^{\circ}$ fabric ply and " 45 " represents a $0^{\circ}-90^{\circ}$ fabric ply rotated by $45^{\circ}$. The measured bondline thickness averaged $0.178 \mathrm{~mm}$. Specimens were $25.4-\mathrm{mm}$ wide and $177.8-\mathrm{mm}$ long. The properties of the graphite/epoxy material and the adhesive were measured at Boeing and are part of the standard design database for the V-22 tilt-rotor aircraft. Typical properties are summarized in Table 1.

Four quasi-static tension tests with a gage length of $101.6 \mathrm{~mm}$ were performed as outlined in [7]. The value of the damage onset load was averaged from four tests and determined to be $P=17.8 \mathrm{kN}$ with a coefficient of variation of $8.9 \%$. The tests were terminated when the flange debonded from the skin. Damage was documented from photographs of the polished specimen edges at each of the four flange corners identified in Figure 1(a). Corners 1 and 4 and corners 2 and 3 had identical damage patterns. The damage at corners 2 and 3, formed first and consisted of a matrix crack in the $45^{\circ}$ skin surface ply and a 
delamination at the $+45^{\circ} / 45^{\circ}$ interface as shown in Figure 1(b). Therefore, this damage pattern was the focus of the current and related earlier analyses [7].

The complex nature of the failure observed during the experiments, where the delamination changed across the specimen width from a delamination running at the skin surface $45^{\circ} / 45^{\circ}$ layer interface to a delamination propagating in the bondline above, suggests the need for a three-dimensional model [7]. Since many layers of brick elements through the thickness would be required to model the individual plies, the size of three-dimensional finite element models, however, may become prohibitively large. Twodimensional models of a longitudinal cut through the specimen allow for a detailed modeling of the individual plies and the adhesive in thickness direction. Two-dimensional models are preferred by industry due to the fact that modeling time, as well as computational time, remains affordable, especially if many different configurations have to be analyzed during the initial design phase. These models have been used extensively during previous studies [2-4, 6, 7]. However, it is inherent to any two-dimensional finite element model that the geometry, boundary conditions and other properties are constant across the entire width.

The current study presents an intermediate step where three-dimensional models were created by extruding two-dimensional models across the width. The fact that the delamination changed across the specimen width from a delamination running at the skin surface $45^{\circ}-45^{\circ}$ layer interface to a delamination propagating in the bondline above, however, is still not accounted for in this model. Nevertheless, the three-dimensional model takes width effects into account and therefore provides insight into the limitations of the use of two-dimensional finite element models. For future detailed modeling and analysis of the damage observed during the experiments, the shell/3D modeling technique [11] offers great potential for saving modeling and computational effort because only a relatively small section in the vicinity of the delamination front needs to modeled with solid elements.

The objective of the current study was to evaluate how the assumptions made in developing twodimensional finite element models of the specimen would effect the damage onset prediction for skinstiffener debonding. Geometrically nonlinear finite element analyses were performed using ABAQUS ${ }^{\circledR}$ two-dimensional plane-stress, plane-strain and generalized plane strain elements. Additionally, two different methods to create generalized plane strain conditions were studied $[12,13]$. The results were compared to data obtained from full three-dimensional simulations to study the feasibility and limitations of using simple two-dimensional models. Computed transverse tensile stresses in the skin surface $45^{\circ}$ layer, flange and skin strains, as well as mixed mode strain energy release rates were compared. 


\section{ANALYSIS FORMULATION}

\section{Two-Dimensional Finite Element Models}

Several assumptions are possible in two-dimensional models. A plane-stress model imposes the out of plane stresses to be zero $\left(\sigma_{\mathrm{zz}}=\tau_{\mathrm{xz}}=\tau_{\mathrm{yz}}=0\right)$ at the free edge of each ply and allows the displacement to be the free parameter. The plane-strain model, on the other hand, imposes the out of plane strains to be zero $\left(\varepsilon_{\mathrm{zz}}=\gamma_{\mathrm{xz}}=\gamma_{\mathrm{yz}}=0\right)$ at the free edge, which excessively constrains the plies. Hence, the two dimensional plane stress and plane strain conditions may serve as upper and lower limits compared to the threedimensional solution.

An outline of the two-dimensional model of the specimen showing the boundary conditions, and loads applied is shown in Figure 2. Finite element models for an undamaged and a damaged specimen were developed using a refined mesh in the critical area of the $45^{\circ}$ skin ply where cracking was observed during the tests. Outside the mesh refinement area, all plies were modeled with one element through the ply thickness. In the refined region, four elements were used per ply thickness for the first two individual flange plies above the bondline and the top skin ply below the bondline as shown in Figures 2(b) and (c) and described in more detail in reference [7]. Four elements through the thickness were also used to model the adhesive film. Ply properties and adhesive material properties used in this study are summarized in Table 1.

Damage in the form of a matrix crack in the top $45^{\circ}$ skin ply that developed into a delamination in the $45^{\circ} / 45^{\circ}$ interface is shown in Figure 1(b). Delaminations of various lengths were modeled by discrete discontinuities as shown in Figure 2(c). The delamination propagating in a bimaterial interface $\left(45^{\circ} / 45^{\circ}\right)$ may, for small element lengths $\Delta a$ at the crack tip, result in incorrect mode separation of the total energy release rate. This effect is caused by the oscillatory singularity at the crack tip [14]. To avoid the effect, for the current investigation the element length $\Delta a$ was chosen to be about $1 / 3$ of the ply thickness. At the opposite taper, the original mesh created for the model of the undamaged specimen was used. Finite element solutions were obtained using the commercial ABAQUS ${ }^{\circledR} /$ Standard finite element software. Eight-noded quadrilateral plane-stress (CPS8R) and plane-strain (CPE8R) elements with quadratic shape functions and a reduced $(2 \times 2)$ integration scheme were utilized for the geometric nonlinear analyses [15].

\section{Generalized Plane Strain Models}

One alternative to a full three-dimensional simulation that requires about the same modeling effort as the simple two-dimensional models is a generalized plane-strain model. Generalized plane strain elements provided by ABAQUS ${ }^{\circledR}$ code are typically used to model a section of a long structure that is free to expand or is subjected to loading perpendicular to the plane of modeling. The formulation involves a model that lies between two planes that can move with respect to each other, and hence, cause strain in the direction perpendicular to the plane of the model that varies linearly with respect to position in the planes 
[15]. Ten-noded quadrilateral generalized plane-strain (CGPE10R) elements with quadratic shape functions and a reduced $(2 \times 2)$ integration scheme were used in the current models. The models shown in Figure 2 were modified to use generalized plane strain analysis. Each element was assigned two additional nodes, which determined the position of the bounding planes and were common to all the elements.

A different approach to create a generalized plane strain case was suggested by Minguet [12]. The generalized plane-strain case is regarded as an intermediate state between plane strain and plane stress, and assumes that the out of plane normal strain $\varepsilon_{z z}=-V_{\mathrm{L}} \varepsilon_{\mathrm{xx}}$, where $V_{\mathrm{L}}$ is the laminate Poisson's ratio, and the shear strain $\gamma_{x z}=\gamma_{y z}=0$. With these assumptions, ply stiffnesses were calculated for each ply angle in the specimen and entered as material properties for the two-dimensional models shown in Figure 3. Eight-noded quadrilateral plane-stress (CPS8R) elements with quadratic shape functions and a reduced (2x2) integration scheme were used for this analysis.

Another possibility to create a two-dimensional generalized plane strain model was described by König [13]. The model is obtained by using one row of three-dimensional brick elements instead of plate, shell or membrane elements. Therefore, the two-dimensional models shown in Figures 2(b) and (c) were extruded into the models shown in Figures 3(b) and (c). This resulted in a $0.1 \mathrm{~mm}$ wide model made of one row of brick elements (C3D20R) with quadratic shape functions and a reduced integration scheme. The advantage of this model is the inclusion of three-dimensional effects in this two-dimensional finite element model. However, the number of degrees of freedom almost quadruple in comparison with membrane elements. The model may be compared to a wall, where one side of the model represents the midplane and the other side is a parallel plane. The midplane of the specimen as shown Figure 3(b) is a plane of symmetry and remains plane under the applied load. The displacements perpendicular to the plane are surpressed $(w=0)$ at all nodes in the midplane. All displacements in the $\mathrm{z}$ - direction at the nodes of the parallel plane are coupled to a constant value $w$. In ABAQUS ${ }^{\circledR}$ the coupling is achieved by grouping all nodes in the parallel plane except for one. The $w$ displacement of all the nodes grouped is then set equal to the $w$ displacement of the one node not included in the group using a linear constraint equation. These coupled displacements at the parallel plane will generate stress resultants at each node of this plane, but the summation of these stress resultants has to vanish because of the zero load in this direction.

\section{Three-Dimensional Finite Element Model}

The three-dimensional model of the specimen with load and boundary conditions is shown in Figure 4(a). The specimen was modeled with ABAQUS ${ }^{\circledR}$ solid twenty-noded hexahedral elements (C3D20R) with quadratic shape functions and a reduced integration scheme. Two-dimensional models of the undamaged and damaged specimen were created first in the $x-y$ plane, and were then extruded into ten elements across the width of the specimen as shown in Figures 4(b) and (c). Although these threedimensional models are not fine enough in the vicinity of the free edges $(z=0.0$ and $z=25.4)$ to accurately capture the influence of the free edges on the distribution of the stresses and energy release rates across the width they are able to account for width effects that two-dimensional models do not include. 
The same refined mesh as in the two-dimensional model (Figure 2) was used in the critical area of the $45^{\circ}$ skin ply where cracking was observed during the tests. Outside the refined area, the mesh was modified to prevent the three-dimensional model from becoming excessively large (Figure 4(b)). The skin plies were grouped into three layered elements with -45/45/90, 90/-45/45 and 0/45/-45 respectively, thus taking advantage of the composite solid element option in ABAQUS ${ }^{\circledR}$ [15]. The fabric layers were grouped into two layered elements as shown in Figure 4(b). In the transition region at the flange several plies were modeled by one element with material properties smeared using the rule of mixtures [16]. The procedure did not ensure the full A-B-D contribution of the plies but appeared suitable for the small transition region to enforce a reasonable model size. The final model had 32,090 elements and 145,432 nodes, yielding a total of 436,296 degrees of freedom.

\section{ANALYTICAL INVESTIGATION}

\section{Global Response}

First, the global response of the specimens was computed at the mean quasi-static damage onset load $(P=17.8 \mathrm{kN})$ determined from experiments. The load-strain behavior computed from different FE models was compared to the corresponding experimental results. This global response was used to examine whether the FE models, the boundary conditions, the loads and the material properties used in the model yielded reasonable results. Strains were averaged from computed nodal point values over a length corresponding to the dimensions of the strain gages shown in Figure 1(a) [7].

A schematic of the deformed geometry, the boundary conditions, and the load applied in the simulations is shown in Figure 2(a). In the schematic, the elongation of the specimen caused by the applied tensile load is shown. The bending effect caused by the load eccentricity in the flange region, the asymmetric layup with respect to the neutral axis, and the membrane stiffening effect is also shown.

A comparison of measured strains at the surface of the flange and computed results is shown in Figure 5. The plane-strain model was stiffer, yielding an upper bound, and the plane-stress model was more compliant, yielding a lower bound compared to the results from the other models. The results from the generalized plain strain models and the full three-dimensional model agree best with the strain recorded during the tests.

In Figure 6, measured strains at the surface of the top $45^{\circ}$ skin ply near the flange tip (see Figure 1(a)) and computed surface strains were compared. Scatter in the experiments can not be shown as only one test was equipped with a strain gage on the skin. As mentioned above, the plane-strain models showed a stiffer behavior and the plane-stress models a more compliant behavior compared to the tested specimen. The results from two of the generalized plain strain cases and the full three-dimensional model fall between the results from the plane stress and plane strain simulation, however, appear stiffer when compared to this single test. The generalized plain strain model suggested by König [13]. yields results similar to the plane stress model. 


\section{Local Response}

A stress analysis was used to study the initial damage in the form of matrix cracking. The maximum principal tensile stress, $\sigma_{\mathrm{tt}}$, normal to the fiber direction was calculated for the static failure load using the two-dimensional and three-dimensional finite element models introduced in the previous section. The stress distribution in the top $45^{\circ}$ skin ply is plotted in the immediate vicinity of the flange tip in Figure 7. In the graph, $x=0$ corresponds to left grip as shown in Figures 2 to 4 , and $x=26.4$ corresponds to the left flange tip. During the fatigue tests, first matrix cracking was observed at locations right next to the flange tip which corresponds to the location where peak stresses were calculated [7].

The transverse tensile strength and scatter band, for IM7/8552, obtained from three-point bending tests of $90^{\circ}$ lamina, were added to the plot for comparison [17]. Stresses at the static failure load computed from the plane-stress analysis correspond with the transverse tensile strength. Stresses from the planestrain analysis are excessively high. This is caused by the constraints inherent to the plane-strain model, particularly in the $\pm 45^{\circ}$ plies.

A fracture mechanics approach was used to investigate delamination onset once the initial crack had formed. During a series of nonlinear finite element analyses, strain energy release rates were computed at each front location for the loads applied in the experiments. A critical energy release rate, $G_{c}$, needs to be determined to predict delamination onset. This critical $G$ is generally identified based on the shape of the total energy release rate versus delamination length curve, which is determined through analysis as shown in Figure 8. The $G_{T}$ versus $x$ curve reached a peak at some virtual delamination length and then decreased. The delamination was extended to a total simulated length of $2.2 \mathrm{~mm}$ to ascertain that the peak value had been captured. The total energy release rates computed for all two-dimensional and generalized plane strain models are plotted in Figure 8. The values obtained from three-dimensional analysis along the centerline of the specimen $(z=12.7)$ was included in Figure 8. Qualitatively, all results follow the same trend. After a small initial drop the computed total energy release rate increases sharply with delamination length, reaches a peak value and gradually decreases. As expected the values from plane stress and plane strain analysis form an upper and lower bound, except for very short delamination lengths. Results from generalized plane strain models and the three-dimensional model fall between the results from twodimensional analysis. The generalized plain strain model suggested by König yields results closer to those obtained from the plane stress model. All generalized plane strain peak $G_{T}$ results are within $8.5 \%$ of the results obtained from full three-dimensional analysis at the center of the specimen.

The variation of mixed mode ratio $G_{S} / G_{T}$ with delamination length is shown in Figure 9 . Here $G_{S}$ denotes the sum of the in-plane shearing components $G_{I I}+G_{I I}$, and $G_{T}$ denotes the total energy release rate $G_{I}+G_{I I}+G_{I I}$, where $G_{I}$ is the opening mode. For two-dimensional analyses, where $\underline{G}_{\underline{I I}}=0$, this definition is equal to the previously used definition of the mixed mode ratio, $G_{I I} / G_{T}$. For three-dimensional analysis, which also yields results for the scissoring mode $G_{I I}$ the modified definition of $G_{S}$ is introduced. All analyses yield the same trend, where the delamination initially starts with high shearing components, followed by a drop which is equivalent to an increase in $G_{I}$. For longer delaminations a gradual increase in 
shearing components is observed. For a more realistic comparison of the $G_{I I}$ contribution from twodimensional and three-dimensional models results from the three-dimensional analysis were calculated assuming $G_{S}=G_{I I}$ and ignoring $G_{I I r}$ As Figure 9 shows, these results fall between the results from twodimensional analysis, for longer delamination lengths. For $G_{S}=G_{I I}+G_{I I P}$ the contribution of the in-plane shearing component is larger compared to the mode ratios obtained from two-dimensional analysis.

\section{CONCLUDING REMARKS}

The influence of the assumptions made in developing two-dimensional finite element models on skin-stiffener debonding specimens was studied. Geometrically nonlinear finite element analyses using two-dimensional plane-stress and plane-strain elements as well as three different generalized plane strain type approaches were performed. The computed skin and flange strains, transverse tensile stresses and energy release rates were compared to results obtained from three-dimensional simulations.

The plane stress and plane strain models provided results for skin and flange strains, as well as energy release rates, which form an upper and lower bound of the results obtained from full threedimensional analysis. The results from generalized plane strain models fall between the results obtained from plane stress and plane strain models. The generalized plane strain models capture the surface strains on the flange and skin very well and computed energy release rates are within $9 \%$ of the results from three-dimensional analysis. Transverse tensile stresses obtained from plane strain and generalized plane strain models, however were excessively high when compared to results from three-dimensional analysis. The stresses from full three-dimensional analysis were lower than results from any of the two-dimensional models, but are closest to the plane stress results.

In general, two-dimensional models are preferred by industry because modeling time, as well as computational time, remains affordable, especially if many different configurations have to be analyzed during the initial design phase. Based on the results of this investigation it is therefore recommended to use results from plane stress and plane strain models as upper and lower bounds. Two-dimensional models may also be used to qualitatively evaluate the stress distribution in a ply and the variation of energy release rates and mixed mode ratios with delamination length.

\section{AKNOWLEDGEMENTS}

This work was performed as part of a Cooperative Research and Development Agreement (CRDA) between the U.S. Army Research Laboratory, Vehicle Technology Directorate located at NASA Langley Research Center, and Boeing, Philadelphia. 


\section{REFERENCES}

[1] P. J. Minguet, M. J. Fedro, T. K. O'Brien, R. H. Martin, and L. B. Ilcewicz, "Development of a Structural Test Simulating Pressure Pillowing Effects in Bonded Skin/Stringer/Frame Configuration," in Proceedings of the Fourth NASA/DoD Advanced Composite Technology Conference, Salt Lake City, Utah, 1993.

[2] P. J. Minguet and T. K. O'Brien, "Analysis of Test Methods for Characterizing Skin/Stringer Debonding Failures in Reinforced Composite Panels," in Composite Materials: Testing and Design (Twelfth Volume), ASTM STP 1274, 1996, pp. 105--124.

[3] P. J. Minguet and T. K. O'Brien, "Analysis of Composite Skin/Stringer Bond Failures Using a Strain Energy Release Rate Approach," in The Tenth International Conference on Composite Materials, vol. I, A. Poursartip and K. Street, Eds., 1995, pp. 245--252.

[4] P. J. Minguet, "Analysis of the Strength of the Interface Between Frame and Skin in a Bonded Composite Fuselage Panel," in The 38rd AIAA/ASME/ASCE/AHS/ASC Structures, Structural Dynamics and Materials Conference, 1997, pp. 2783--2790.

[5] M. K. Cvitkovich, T. K. O'Brien, and P. J. Minguet, "Fatigue Debonding Characterization in Composite Skin/Stringer Configurations," in Composite Materials: Fatigue and Fracture, Seventh Volume, ASTM STP 1330: American Society for Testing and Materials, 1998, pp. 97-121.

[6] R. Krueger, M. K. Cvitkovich, T. K. O'Brien, and P. J. Minguet, "Testing and Analysis of Composite Skin/Stringer Debonding Under Multi-Axial Loading," Journal of Composite Materials, vol. 34, pp. 1263-1300, 2000.

[7] R. Krueger, I. L. Paris, T. K. O'Brien, and P. J. Minguet, "Fatigue Life Methodology for Bonded Composite Skin/Stringer Configurations,", NASA-TM-2001-210842, 2001.

[8] E. F. Rybicki and M. F. Kanninen, "A Finite Element Calculation of Stress Intensity Factors by a Modified Crack Closure Integral," Eng. Fracture Mech., vol. 9, pp. 931--938, 1977.

[9] I. S. Raju, "Calculation Of Strain-Energy Release Rates With Higher Order And Singular Finite Elements," Eng. Fracture Mech., vol. 28, pp. 251--274, 1987.

[10] F. G. Buchholz, H. Grebner, K. H. Dreyer, and H. Krome, "2D- and 3D- Applications of the Improved and Generalized Modified Crack Closure Integral Method," in Computational Mechanics '88, S. N. a. Y. Atluri, G., Ed., 1988.

[11] R. Krueger and T. K. O'Brien, "A Shell/3D Modeling Technique for the Analysis of Delaminated Composite Laminates," Composites Part A: applied science and manufacturing, vol. 32, pp. 2544, 2001.

[12] D. M. Hoyt, S. H. Ward, and P. J. Minguet, "Strength and Fatigue Life Modeling of Bonded Joints in Composite Structure," in Proceedings of the American Society for Composites - 15th Annual Technical Conference on Composite Materials: Technomic Publishing, 2000, pp. 729736.

[13] M. König, R. Krüger, E. Kohler, M. Kurz, and T. Ruckstuhl, "Analytical and Numerical Analysis of a Specimen Containing a Delamination Caused by a Ply Cut," Institute for Statics and Dynamics of Aerospace Structures, University of Stuttgart ISD-Report No. 97/2, Rev. B, 1999. 
[14] I. S. Raju, J. H. Crews, and M. A. Aminpour, "Convergence of Strain Energy Release Rate Components for Edge-Delaminated Composite Laminates," Eng. Fracture Mech., vol. 30, pp. 383$-396,1988$.

[15] ABAQUS/Standard - User's Manual - Version 5.6, vol. II: Hibbitt, Karlsson \& Sorensen, Inc., 1996.

[16] S. W. Tsai and H. T. Hahn, Introduction to Composite Materials, Technomic Publishing Co., Inc., 1980.

[17] T. K. O'Brien, A. D. Chawan, and K. DeMarco, "Influence of Specimen Preparation and Specimen Size on Composite Transverse Tensile Strength and Scatter,", NASA/TM-2001-211030, ARL-TR2540, 2001. 


\section{TABLES}

TABLE 1. MATERIAL PROPERTIES

\begin{tabular}{|c|c|c|}
\hline \multicolumn{3}{|c|}{ IM7/8552 Unidirectional Graphite/Epoxy Prepreg } \\
\hline$E_{11}=161.0 \mathrm{GPa}$ & $E_{22}=11.38 \mathrm{GPa}$ & $E_{33}=11.38 \mathrm{GPa}$ \\
\hline$v_{12}=0.32$ & $v_{13}=0.32$ & $v_{23}=0.45$ \\
\hline$G_{12}=5.17 \mathrm{GPa}$ & $G_{13}=5.17 \mathrm{GPa}$ & $G_{23}=3.92 \mathrm{GPa}$ \\
\hline \multicolumn{3}{|c|}{ IM7/8552 Graphite/Epoxy Plain Weave Fabric } \\
\hline$E_{11}=71.7 \mathrm{GPa}$ & $E_{22}=71.7 \mathrm{GPa}$ & $E_{33}=10.3 \mathrm{GPa}$ \\
\hline$v_{12}=0.04$ & $v 13=0.35$ & $v 23=0.35$ \\
\hline$G_{12}=4.48 \mathrm{GPa}$ & $G_{13}=4.14 \mathrm{GPa}$ & $G_{23}=4.14 \mathrm{GPa}$ \\
\hline \multicolumn{3}{|c|}{ Grade 5 FM300 Adhesive } \\
\hline$E=1.72 \mathrm{GPa}$ & $v=0.3$ & (assumed isotropic) \\
\hline
\end{tabular}




\section{FIGURE CAPTIONS}

Figure 1: Skin/Flange Specimen

(a) Specimen Configuration

(b) Detail of typical damage patterns at the specimen corners 2 and 3 [7]

Figure 2: Two-dimensional finite element model of skin/flange specimen

(a) Outline of model with load and boundary conditions

(b) Detail of model of undamaged specimen

(c) Detail of deformed model of damaged specimen

Figure 3: Three-dimensional generalized plane strain model of skin/flange specimen

(a) Three-dimensional generalized plane strain model with load and boundary conditions

(b) Detail of model of undamaged specimen

(c) Detail of deformed model of damaged specimen

Figure 4: Full three-dimensional model of skin/flange specimen

(a) Three-dimensional model with load and boundary conditions

(b) Detail of model of undamaged specimen

(c) Detail of deformed model of damaged specimen

Figure 5: Flange strain-load plots for quasi-static tests

Figure 6: Typical skin strain-load plots for quasi-static tests

Figure 7: Computed transverse tensile stress results in top $45^{\circ}$ skin ply

Figure 8: Computed total energy release rate for delamination growing from matrix crack in skin top $45 \%$ $45^{\circ}$ ply interface

Figure 9: Computed mixed mode ratio $G_{S} / G_{T}$ for delamination growing from matrix crack in skin top $45^{\circ} / 45^{\circ}$ ply interface 

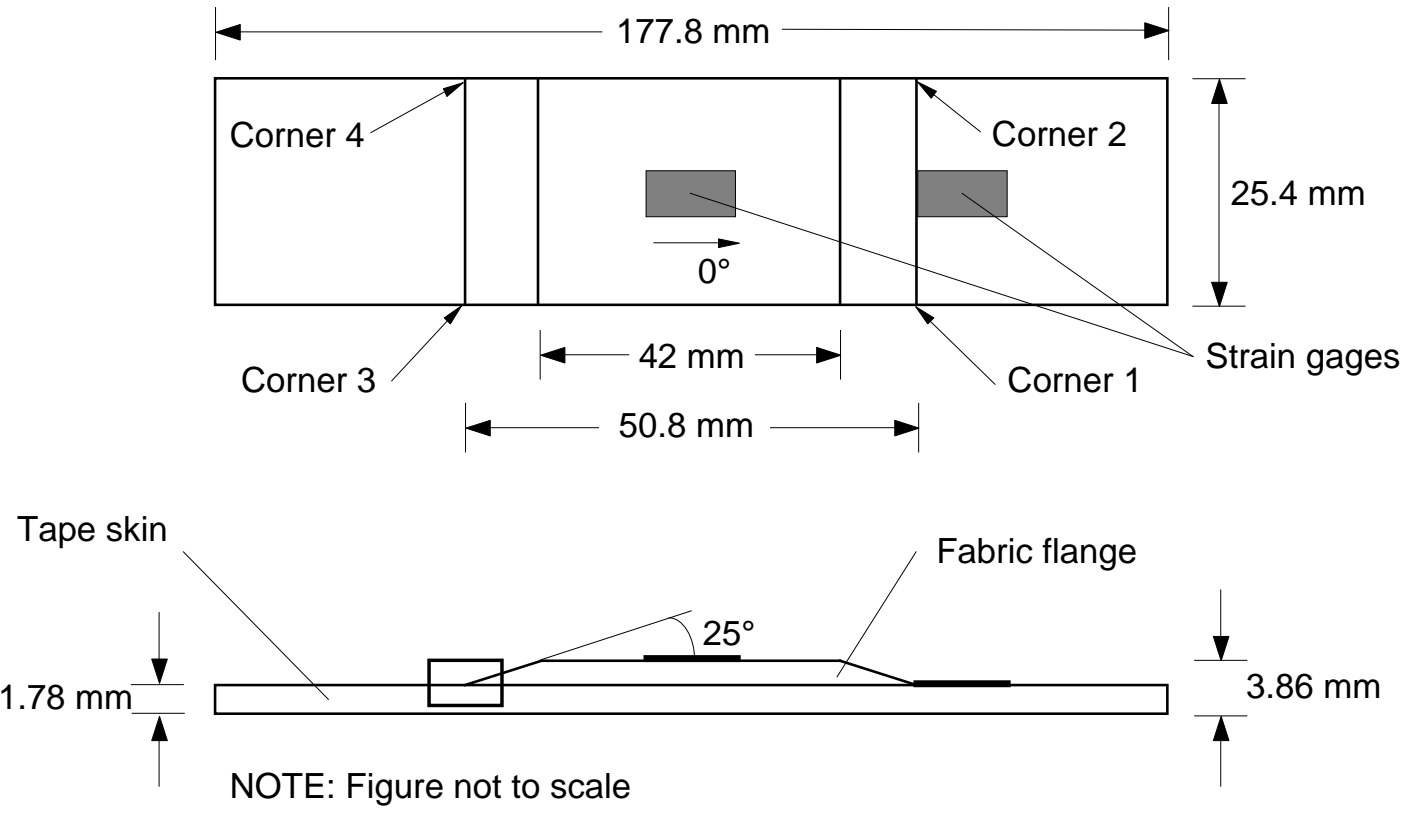

(a) Specimen configuration

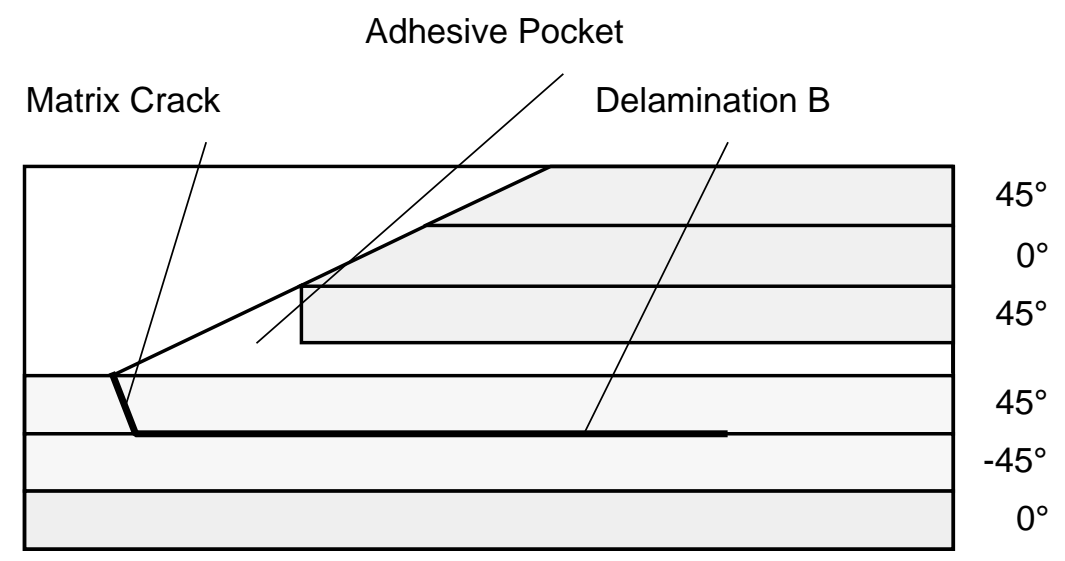

(b) Detail of typical damage patterns at specimen corners 2 and 3 [7]

Figure 1. Skin/Flange Specimen 


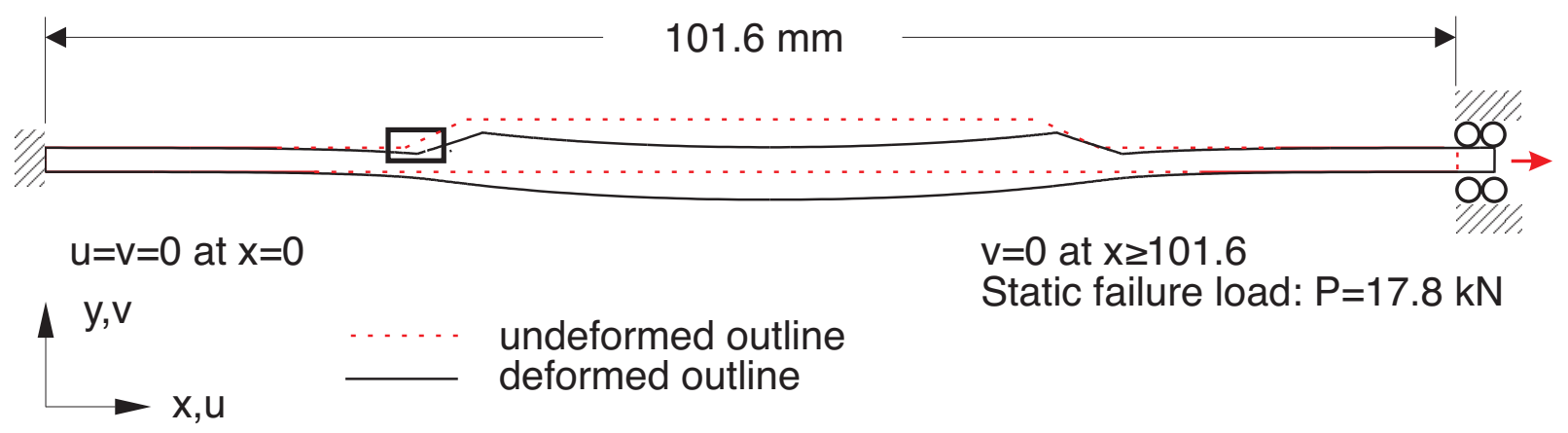

(a) Outline of model with load and boundary conditions

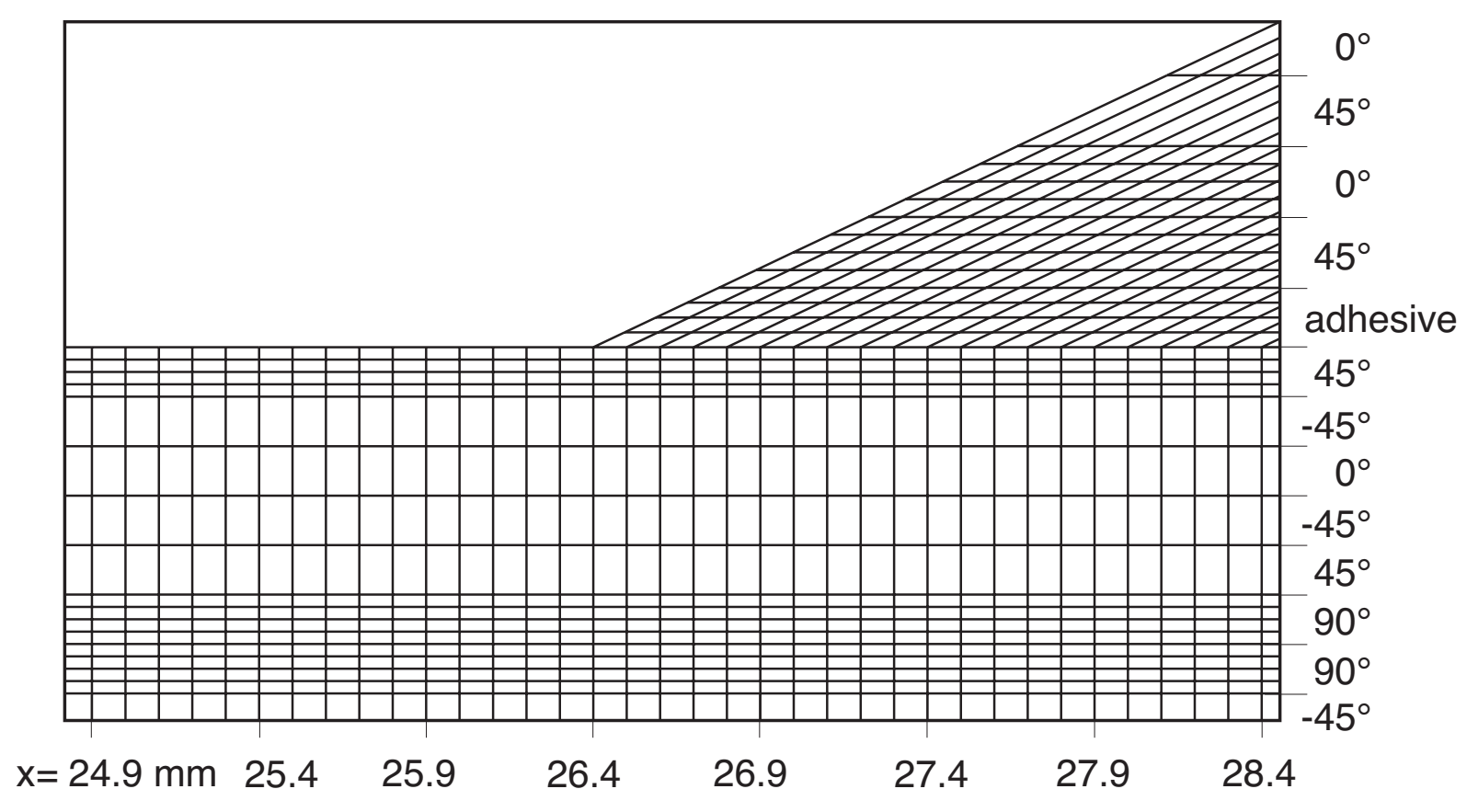

(b) Detail of model of undamaged specimen

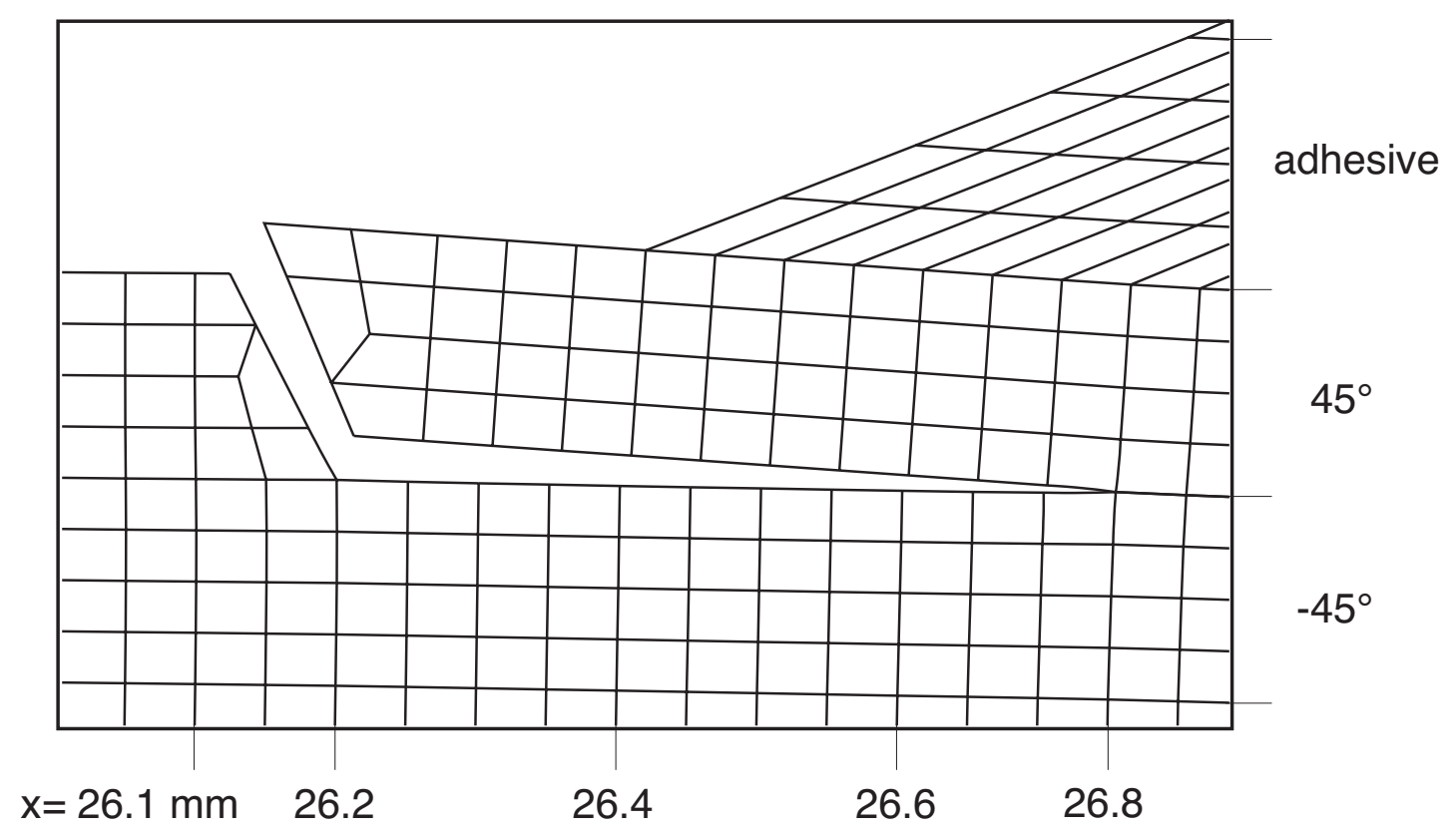

(c) Detail of deformed model of damaged specimen

Figure 2. Two dimensional finite element model of skin/flange specimen 


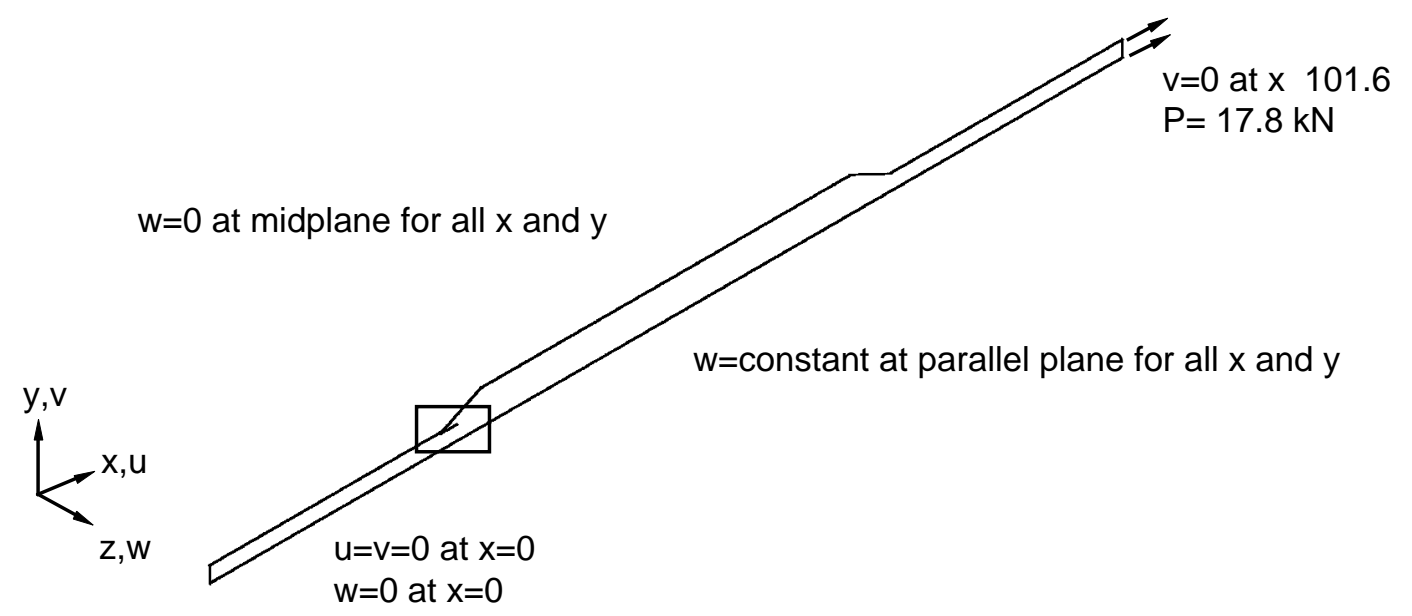

(a) Three-dimensional plane strain model with load and boundary conditions

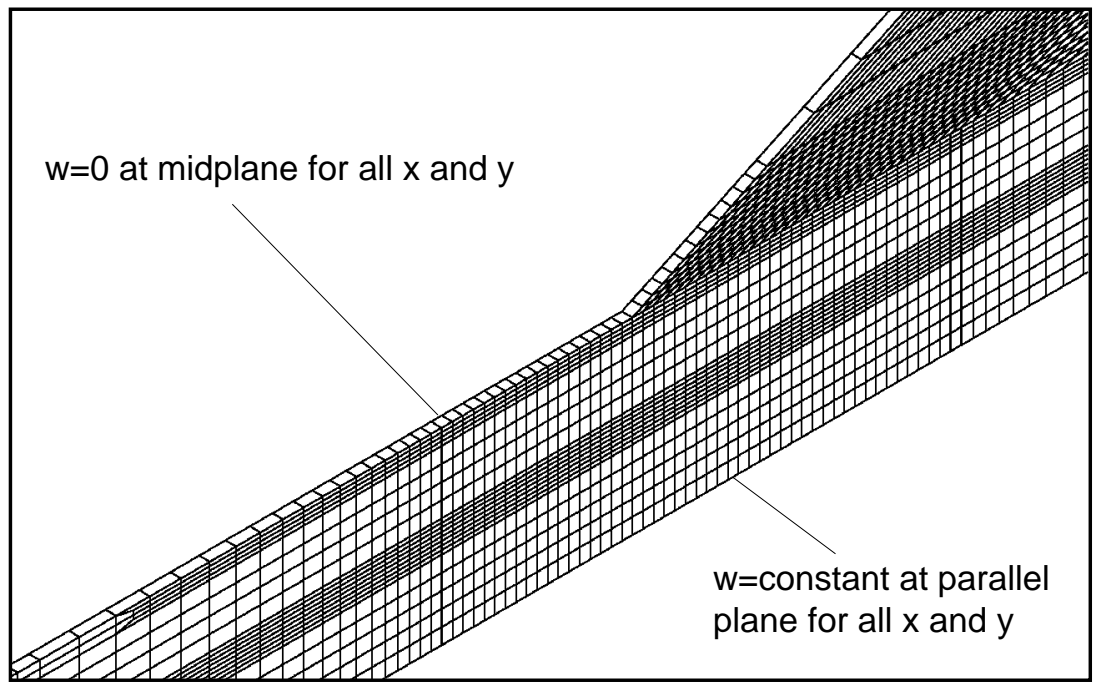

(b) Detail of model of undamaged specimen

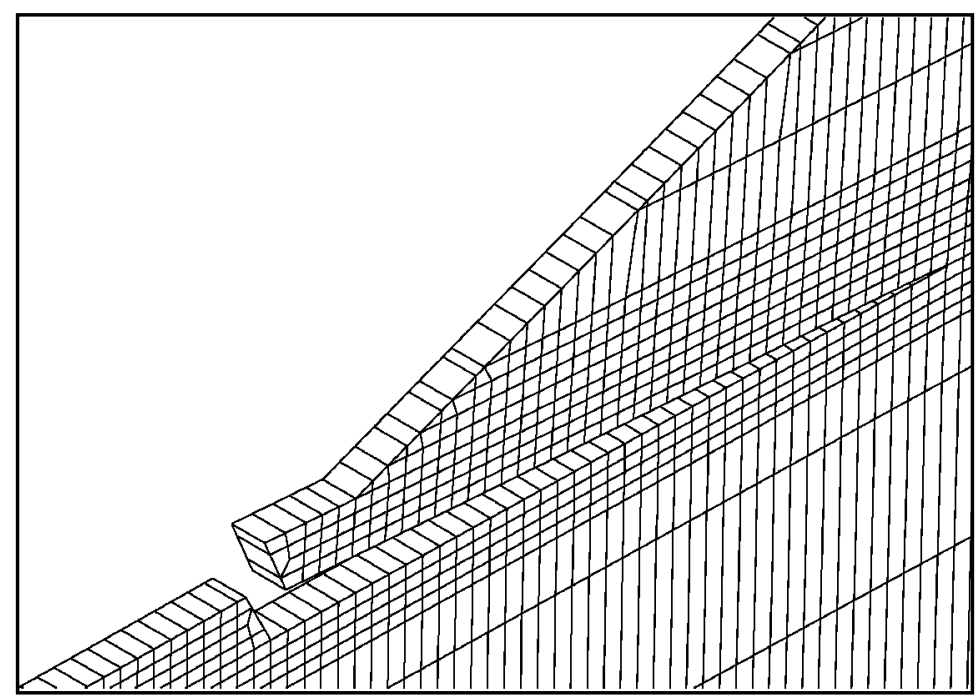

(c) Detail of deformed model of damaged specimen

Figure 3. Three-dimensional generalized plane strain model of skin/flange specimen 


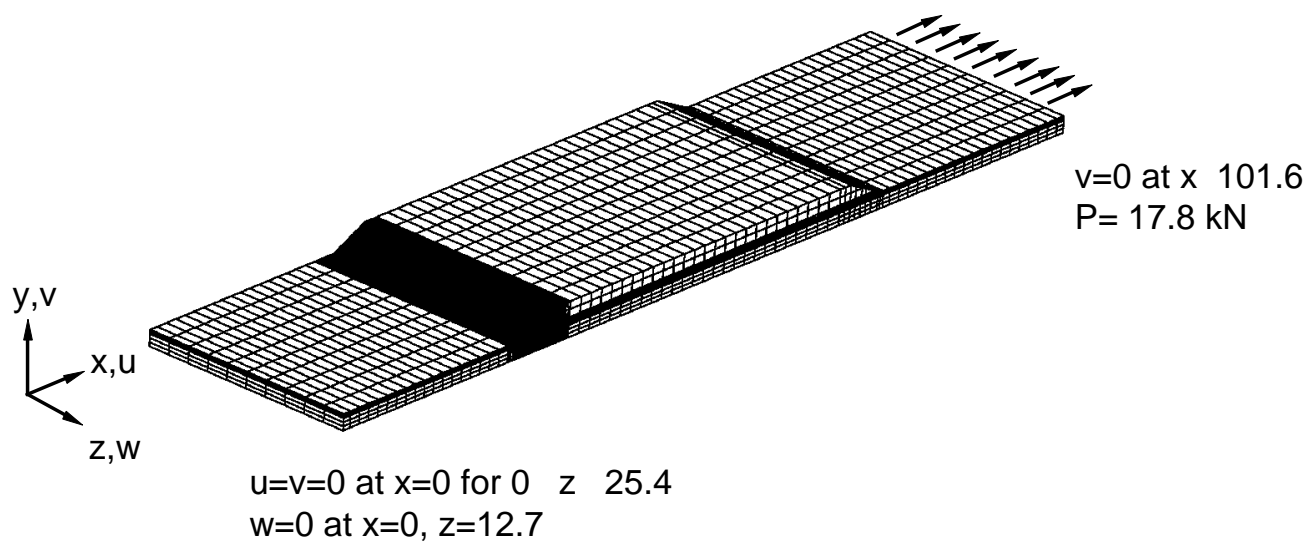

(a) Three-dimensional model with load and boundary conditions

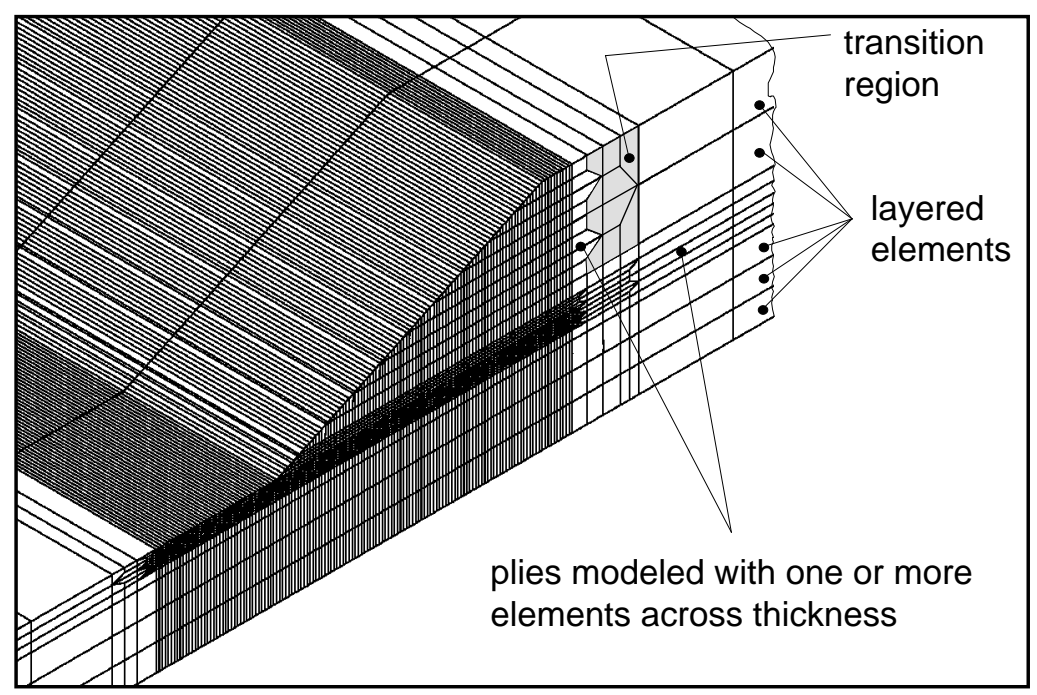

(b) Detail of model of undamaged specimen

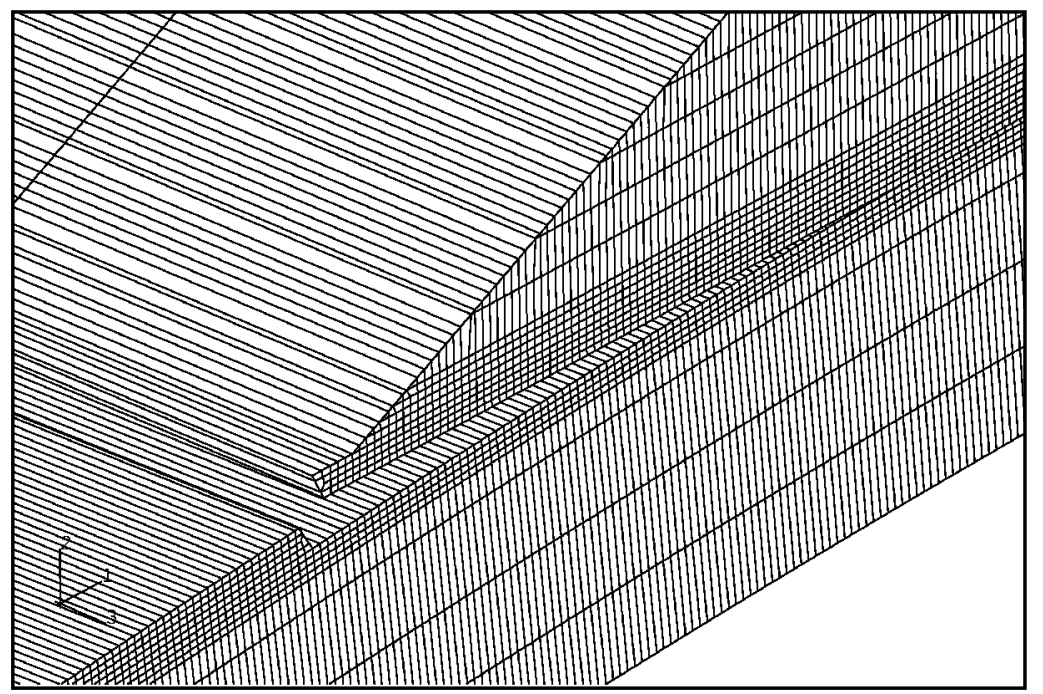

(c) Detail of deformed model of damaged specimen

Figure 4. Full three-dimensional model of skin/flange specimen 


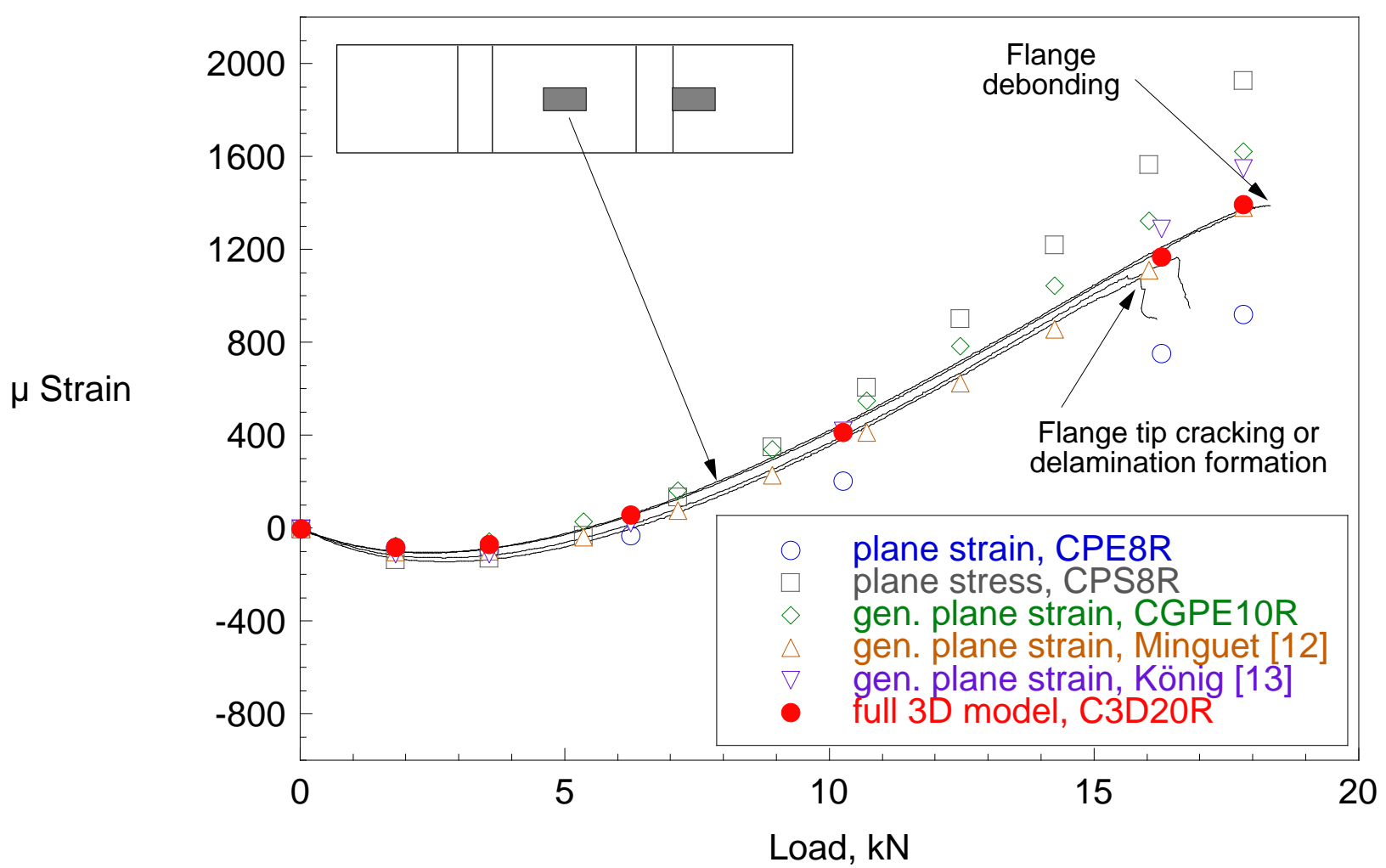

Figure 5. Flange strain-load plots for quasi-static tests.

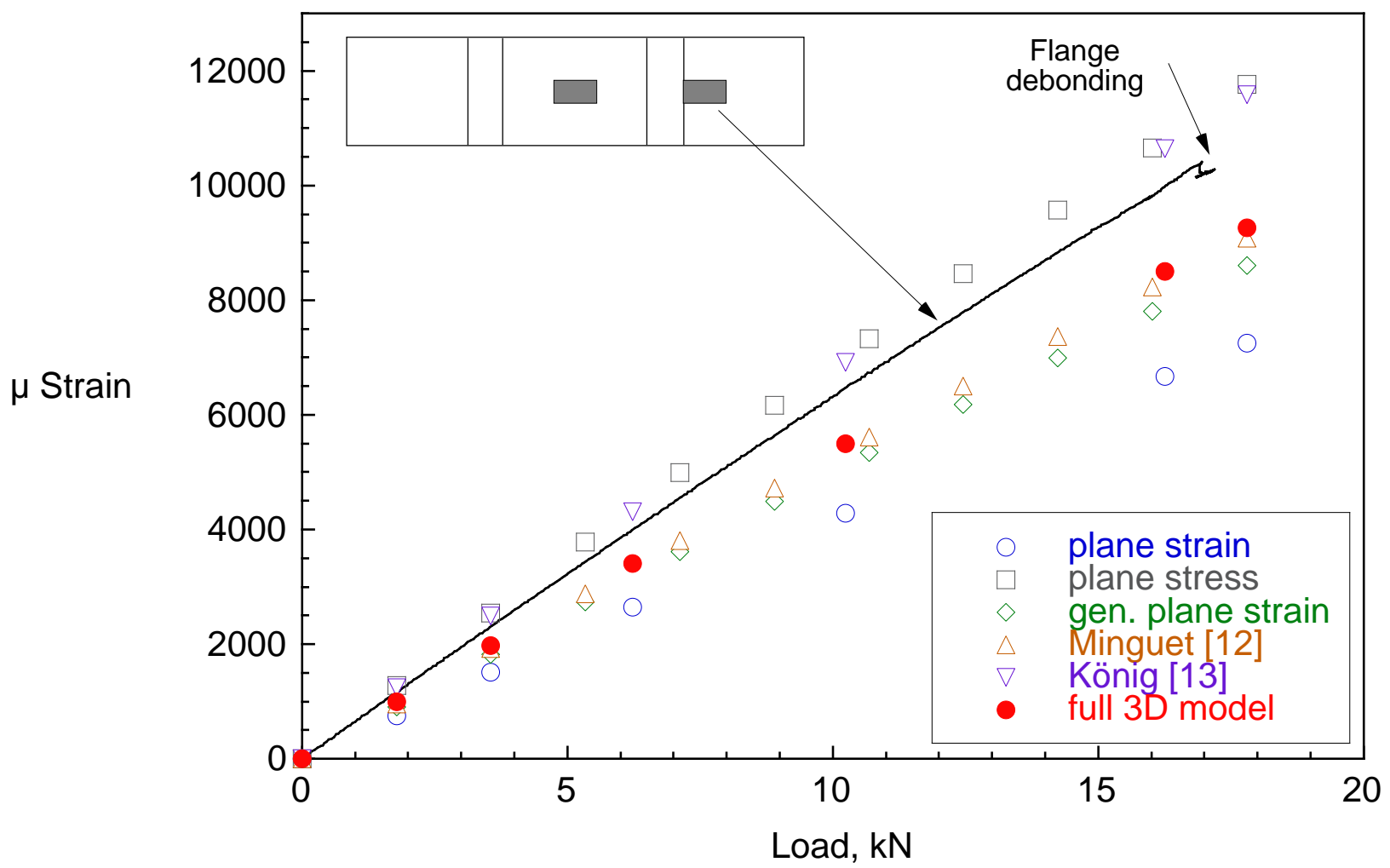

Figure 6. Typical skin strain-load plot for quasi-static tests. 


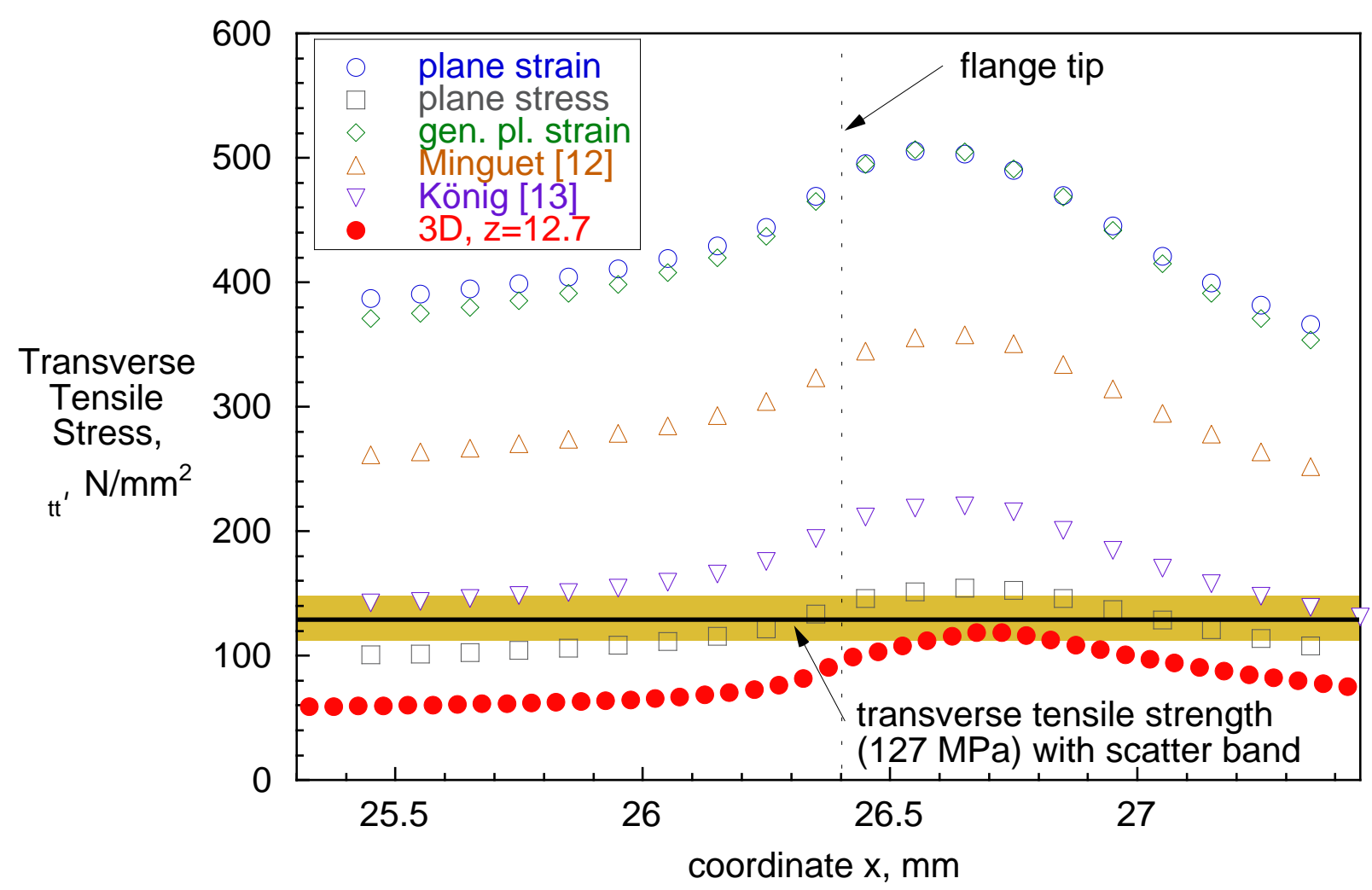

Figure 7. Computed transverse tensile stress results in top $45^{\circ}$ skin ply.

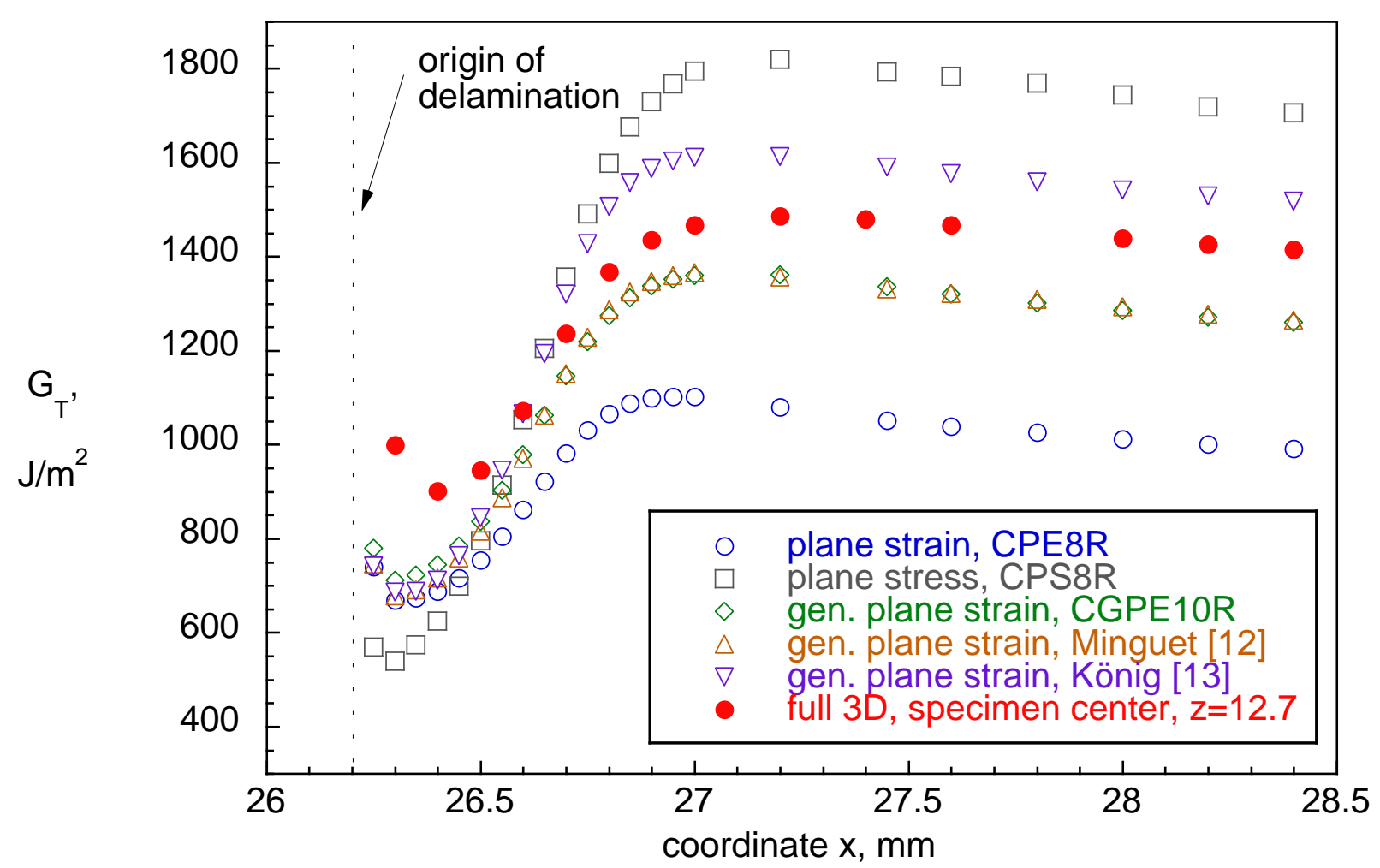

Figure 8. Computed total energy release rate for delamination growing from matrix crack in skin top $45^{\circ} /-45^{\circ}$ ply interface 


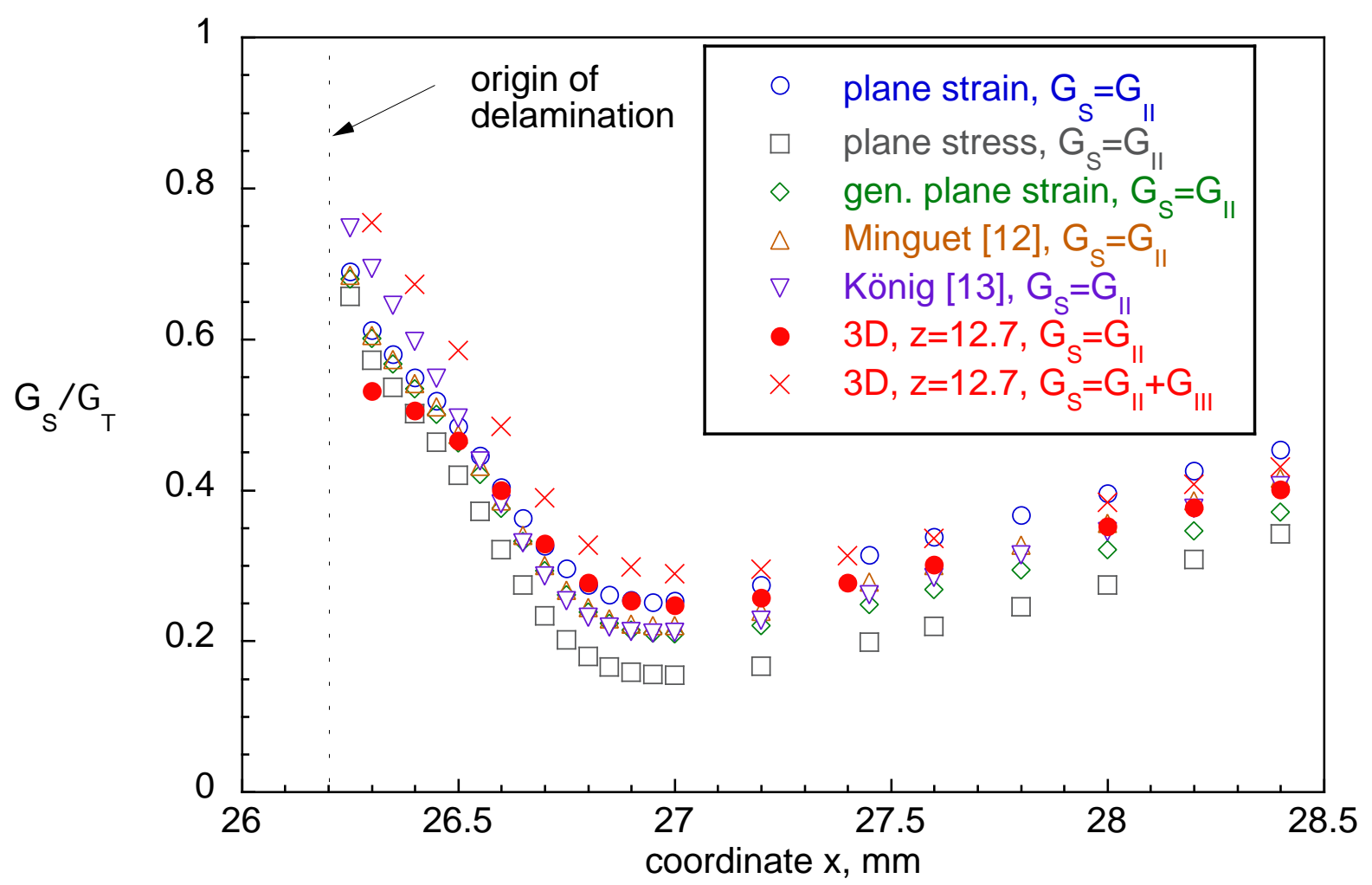

Figure 9. Computed mixed mode ratio $\mathrm{G}_{\mathrm{S}} / \mathrm{G}_{\mathrm{T}}$ for delamination growing from matrix crack in skin top $45^{\circ} /-45^{\circ}$ ply interface 